\title{
Safety of users in road evacuation: modelling and DSS for pedestrian outflow
}

\author{
M. Di Gangi \\ Department of Civil Engineering, University of Messina, Italy
}

\begin{abstract}
This paper concerns the simulation of pedestrian outflow related to the evacuation of a building. In this paper, after a literature review concerning commercial software suited for the simulation of evacuation, a simulation tool is proposed and a comparison between results obtained from simulations and data recorded from an experimentation on a test site is also presented.
\end{abstract}

\section{Introduction}

In those cases where a forthcoming disaster can be notified in advance, only evacuation represents a chance. During the time interval between notification and effects of the disaster a preventive evacuation can be executed, so a preventive planning of the activities to be executed in emergency conditions is fundamental for an efficient evacuation and to reduce clearance time. For this reason, evacuation calculations are an important part of performance-based analyses in order to assess the level of life safety provided in buildings.

In the last years a variety of commercial, academic and governmental tools were produced to support efficient evacuation planning. The availability of tools and the advent of (relatively) low-cost, high-performance computing platforms encourage public agencies to consider analytical methods to improve their evacuation planning or operational practices.

The tools can be classified as regards the classes of adopted models for transport simulation. They influence the computational complexity of tools and, in general, the tools' capability to facilitate decision-making ranging from realtime to planning exercises.

On the other hand there is also, in certain circumstances, a need for simple tools able to quantify, in terms of evacuation time, the effectiveness of an evacuation plan. 
In this paper, after a classification of some of the most adopted applications for the simulation of evacuation, a comparison of simulated results with those obtained during a real experimentation is conducted.

In particular, the paper is structured as follows: in section 2 it is shown an inventory of pedestrian evacuation tools, section 3 reports a short description of the models and procedures adopted to carry out simulations in a real context. Section 4 presents an analysis of results obtained with the simulations and a comparison between these results and on site experimentation data.

\section{Pedestrian evacuation tools inventory}

Among proposed classifications and reviews, those proposed by Gwynne et al [1], Fire Model Survey [2] and Kuligowski and Peacock [3] can be considered in order to specify a common terminology, structure and data gathering in order to approach a classification of the models.

Adopted classification method

According to definitions given in [3], egress models in this work have been classified considering:

- the perspective of model;

- the perspective of users;

- the modelling method

- the structure of supply model;

- the users' behaviour;

- measurable outputs and visualisation capabilities.

In the following definitions adopted within the classification method are shown.

\section{Perspective of model}

The perspective of the model explains how the model views the users; model views the occupants, there are two ways that a model can view the occupant:

1) Individually: a model with an individual perspective tracks the movement of individuals throughout the simulation and can give information about those individuals (e.g. their positions at points in time throughout the evacuation).

2) Globally: in this case the model sees its occupants as a homogeneous group of people moving to the exits.

An individual perspective of the occupants is more detailed, but which alternative is best depends on the purpose of the simulation. If the user is not interested in knowing the position of each occupant throughout the simulation or assigning individual characteristics to the population, then a global view can be sufficient.

\section{Perspective of users}

The perspective of users explains how the users (occupants) view the building; also in this case two ways can be identified:

1) In an individual view of the building, the user does not know the building's exit paths and decides his/her route based on information from the floor, personal experience, and in some models, the information from the users around him/her. 
2) In a global view of the building the users are familiar with the building and automatically know their best exit path.

\section{Modelling Method}

Under the modelling method category, the following three labels can be individuated:

- Movement models: those models that move users from one point in the building to another (usually the exit or a position of safety).

- Behavioural models: those models that incorporate users performing actions, in addition to movement toward a specified goal (exit).

- Partial behaviour models: those models that primarily calculate user movement, but begin to simulate behaviours. Possible behaviours could be implicitly represented by pre-movement time distributions among the users, unique user characteristics, overtaking behaviour, and the introduction of smoke or smoke effects to the user.

\section{Structure of supply model}

This subcategory is used to assess how users move throughout the building; three categories can be introduces:

- a coarse supply model divides the floor plan into rooms, corridors, stair sections, etc. and the users move from one room to another;

- a fine supply model divides a floor plan into a number of small grid cells that the users move to and from;

- a continuous supply model applies a 2D (continuous) space to the floor plans of the structure, allowing the users to walk from one point in space to another throughout the building.

Using fine and continuous supply models it is possible to simulate the presence of obstacles and barriers in building spaces that influence individual path route choice, whereas the coarse supply models "move" occupants only from one portion of a building to another.

\section{Users' behaviour}

The behaviour of the users is represented using the following labels associated with this sub category:

- $\quad$ None $(\mathrm{N})$ : in these models only the movement aspect of the evacuation is simulated.

- $\quad$ Implicit (I): these models attempt to model behaviour implicitly by assigning certain response delays or occupant characteristics that affect movement throughout the evacuation.

- Conditional (rule-based) (C): these models assign individual actions to a person or group of users that are affected by structural or environmental conditions of the evacuation (i.e. "if, then" behavioural method models).

- Artificial Intelligence (AI): these models attempt to simulate human intelligence throughout the evacuation.

- Probabilistic (P): for these models many of the rules or conditions are stochastic, allowing for the variations in outcome by repeating certain simulations. 
Some models have the capability of assigning probabilities of performing certain behaviours to specific user groups. Many of the partial behavioural models allow for a probabilistic distribution of the pre-evacuation times, travel speeds, and/or smoke susceptibility.

Table 1: $\quad$ Background characteristics of considered models.

\begin{tabular}{|l|c|c|c|}
\hline \multicolumn{1}{|c|}{ TOOL } & COUNTRY & $\begin{array}{c}\text { PERSPECTIVE OF } \\
\text { MODEL }\end{array}$ & $\begin{array}{c}\text { PERSPECTIVE OF } \\
\text { USERS }\end{array}$ \\
\hline ALLSAFE & Norway & Global & Global \\
\hline ASERI & Germany & Individual & Individual \\
\hline BuildingExodus & United Kingdom & Individual & Individual \\
\hline CRISP3 & United Kingdom & Individual & Individual \\
\hline EESCAPE & Austria & Global & Global \\
\hline EGRESS & United Kingdom & Individual & Individual \\
\hline EVACNET4 & United States & Global & Global \\
\hline EXIT89 & United States & Individual & Individual \\
\hline EXITT & United States & Individual & Individual \\
\hline FPETool & United States & Global & Global \\
\hline GridFlow & United Kingdom & Individual & Individual \\
\hline Legion & United Kingdom & Individual & Individual \\
\hline PathFinder & United States & Individual & Global \\
\hline PedGo & Germany & Individual & Individual \\
\hline PEDROUTE & United Kingdom & Global & Global \\
\hline SICURO & Italy & Individual & Global \\
\hline Simulex & United Kingdom & Individual & Individual \\
\hline STEPS & United Kingdom & Individual & Individual \\
\hline TIMTEX & United States & Global & Individual \\
\hline WAYOUT & Australia & Global & Global \\
\hline
\end{tabular}

Table 2: $\quad$ Main features of considered models.

\begin{tabular}{|c|c|c|c|}
\hline TOOL & MODELLING METHOD & $\begin{array}{l}\text { STRUCTURE } \\
\text { OF SUPPLY }\end{array}$ & USER BEHAVIOUR \\
\hline ALLSAFE & Partial Behaviour & Coarse & Implicit \\
\hline ASERI & Behaviour & Continuous & Rule-Based / Conditional \\
\hline BuildingExodus & Behaviour & Fine & Rule-Based / Conditional \\
\hline CRISP3 & Behaviour & Fine & Rule-Based / Conditional \\
\hline EESCAPE & Movement & Coarse & None \\
\hline EGRESS & Behaviour & Fine & Conditional \\
\hline EVACNET4 & Movement & Coarse & None \\
\hline EXIT89 & Partial Behaviour & Coarse & Implicit \\
\hline EXITT & Behaviour & Coarse & Rule-Based / Conditional \\
\hline FPETool & Movement & Other & None \\
\hline GridFlow & Partial Behaviour & Continuous & Implicit \\
\hline Legion & Behaviour & Continuous & Artificial Intelligence \\
\hline PathFinder & Movement & Fine & None \\
\hline PedGo & Movement / Partial Behaviour & Fine & Implicit \\
\hline PEDROUTE & Partial Behaviour & Coarse & Implicit \\
\hline SICURO & Movement / Partial Behaviour & Coarse & None \\
\hline \begin{tabular}{|l|} 
Simulex \\
\end{tabular} & Partial Behaviour & Continuous & Implicit \\
\hline STEPS & Movement / Partial Behaviour & Fine & None \\
\hline TIMTEX & Movement & Coarse & None \\
\hline WAYOUT & Movement & Coarse & None \\
\hline
\end{tabular}


Table 3: $\quad$ Main measurable outputs of considered models.

\begin{tabular}{|c|c|c|}
\hline TOOL & $\begin{array}{l}\text { VISUAL } \\
\text { CAPAB. }\end{array}$ & MAIN MEASURABLE OUTPUTS \\
\hline ALLSAFE & None & $\begin{array}{l}\text { - } \quad \text { Time to fire detection, to react and to interpret the situation } \\
\text { - } \quad \text { Time for users to decide where to escape } \\
\text { Time to evacuate a room or corridor and the building }\end{array}$ \\
\hline ASERI & $2 \mathrm{D} / 3 \mathrm{D}$ & $\begin{array}{l}\text { Evacuation time } \\
\text { Detailed information on the structure and congestion situation that lead } \\
\text { to delay } \\
\text { Mean egress time, along wish their corresponding variances and } \\
\text { confidence intervals }\end{array}$ \\
\hline $\begin{array}{l}\text { BuildingExodu } \\
\text { s }\end{array}$ & $2 \mathrm{D} / 3 \mathrm{D}$ & $\begin{array}{l}\text { A data analysis tool (askEXODUS) allows to extract specific data from } \\
\text { the output files }\end{array}$ \\
\hline CRISP3 & $2 \mathrm{D} / 3 \mathrm{D}$ & $\begin{array}{ll}\text { - } & \text { Detailed information about each person at every time step } \\
\text { - } & \text { Route information, fire conditions in certain locations } \\
\text { - } & \text { Pictorial output }\end{array}$ \\
\hline EESCAPE & None & Total evacuation time \\
\hline EGRESS & $2 \mathrm{D}$ & $\begin{array}{ll}\text { - } & \text { Visualisation of congestion points } \\
\text { - } & \text { Visualisation of bottlenecks } \\
\text { Visualisation of merging flows }\end{array}$ \\
\hline EVACNET4 & None & $\begin{array}{l}\text { - Time to evacuate building, average time for evacuee to egress building, } \\
\text { average number of evacuees per specified time period, number of } \\
\text { - } \quad \text { Nuccessful evacuees } \\
\text { - } \quad \text { List of arcs and number of people travelling through each arc } \\
\text { - } \quad \text { Location of queues and time length of the queue } \\
\text { - } \quad \begin{array}{l}\text { Floor and node clearing time } \\
\text { - }\end{array} \\
\text { Building and destination evacuation profile } \\
\text { Number of people not evacuated by a specified time }\end{array}$ \\
\hline EXIT89 & None & $\begin{array}{l}\text { - User movement table (track the time and corresponding node position of } \\
\text { - } \quad \text { Total evacuation time } \\
\text { - Number of occupants trapped } \\
\text { - } \quad \text { Stair and floor-clearing times }\end{array}$ \\
\hline EXITT & None & $\begin{array}{l}\text { - } \quad \text { Number of users out of the building } \\
\text { - } \quad \text { Number of occupant trapped } \\
\text { - } \quad \text { Action of individual users at all time periods of the simulation }\end{array}$ \\
\hline FPETool & None & $\begin{array}{l}\text { Horizontal and stair travel time } \\
\text { - } \quad \text { Time for all users to pass through exit doors }\end{array}$ \\
\hline GridFlow & $2 \mathrm{D} / 3 \mathrm{D}$ & $\begin{array}{l}\text { - Outputs that can be imported into spreadsheet programs. } \\
\text { Details about population in every space at every logging interval after } \\
\text { each run. } \\
\text { Detailed aspects of the buildings and users. }\end{array}$ \\
\hline Legion & $2 \mathrm{D} / 3 \mathrm{D}$ & $\begin{array}{l}\text { - } \quad \text { Usage maps (space, utilisation, density and speed, etc) } \\
\text { - } \quad \text { Graphs on outflow characteristics } \\
\text { Animations }\end{array}$ \\
\hline PathFinder & $2 \mathrm{D}$ & $\begin{array}{l}\text { - } \quad \begin{array}{l}\text { Number of people that have used an exit } \\
\text { - }\end{array} \quad \text { Time for a stair and a floor to become empty } \\
\text { - } \quad \text { Total evacuation time }\end{array}$ \\
\hline PedGo & $2 \mathrm{D}$ & $\begin{array}{l}\text { - Text files that can be imported into spreadsheet programs (limited } \\
\text { documentation on this model) }\end{array}$ \\
\hline PEDROUTE & $2 \mathrm{D} / 3 \mathrm{D}$ & Details of peak occupancy and average delay per passenger \\
\hline
\end{tabular}


Table 3 Continued.

\begin{tabular}{|c|c|c|}
\hline TOOL & $\begin{array}{l}\text { VISUAL } \\
\text { CAPAB. }\end{array}$ & MAIN MEASURABLE OUTPUTS \\
\hline SICURO & $2 \mathrm{D} / 3 \mathrm{D}$ & $\begin{array}{l}\text { Time to evacuate building, average time for evacuee to egress building, } \\
\text { average number of evacuees per specified time period } \\
\text { Flow characteristics for each arc } \\
\text { Location of queues and time period that arc had a queue } \\
\text { Travel times for each path } \\
\text { Destination evacuation profile } \\
\text { Number of people evacuated by a specified time }\end{array}$ \\
\hline Simulex & $2 \mathrm{D}$ & $\begin{array}{l}\text { 2D visualisation of evacuation } \\
\text { Overall evacuation time of all users reaching the exits } \\
\text { Number of people passing through each exit }\end{array}$ \\
\hline STEPS & $2 \mathrm{D} / 3 \mathrm{D}$ & $\begin{array}{l}\text { Total evacuation rime } \\
\text { Number of users in certain areas, planes and paths } \\
\text { Number of people that have left the different fields versus time }\end{array}$ \\
\hline TIMTEX & None & $\begin{array}{l}\text { Total evacuation rime } \\
\text { Individual floor clearing time }\end{array}$ \\
\hline WAYOUT & $2 \mathrm{D}$ & $\begin{array}{l}\text { Complete movement time } \\
\text { Individual time when each compartment is evacuated }\end{array}$ \\
\hline
\end{tabular}

\subsection{Model classification}

In this short review a total of 20 available computer models have been considered. Many of such models can also simulate evacuation from other types of structures. The considered models, in alphabetical order, are the following: ALLSAFE [4], ASERI [5-7], buildingEXODUS [3, 8-10], CRISP [11, 12], EESCAPE [13], EGRESS [14-16], EVACNET4 [17, 18], EXIT89 [19-21], EXITT [22, 23], FPETool [24], GridFlow [25], Legion [26, 27], PathFinder [28], PedGo [29, 30], PEDROUTE/PAXPORT [31-33], SICURO [34-36], Simulex [37-39], STEPS [40, 41], TIMTEX [42], WAYOUT [43].

Results of review are summarised in the following tables. In particular in Tab. 1 background characteristics of each model are described, Tab. 2 reports main features of each considered model and in Tab. 3 are summarised visualisation capabilities and main measurable outputs available for each considered tool.

\section{Applicative context}

\subsection{The test site}

The considered building is a primary school located within the CBD area selected for the drill [18]. The school evacuation plan stipulates that everybody must gather at a site in front of the building (called first assembly point, see Fig. 1); according to the town evacuation plan, the school's staff and pupils will be led to the refuge area located about $2 \mathrm{~km}$ from the school by means of a bus service starting from another gathering place (second assembly point) as shown in Fig. 2. Hence evacuation of the school was schematized in following five main phases: 1) evacuation of the building reaching first assembly point; 2) rollcall of pupils at first assembly point; 3) transfer to second assembly point; 
4) boarding on bus; 5) transfer to refuge area. In the application here described the analysis focuses on the evacuation of the first three phases.

Data were gathered concerning supply and demand. During the drill a monitoring system was arranged, with manual/automatic tools and 12 video cameras, in order to acquire data concerning pedestrian outflow (times, densities) both inside and outside the building until the gathering places were reached.

\subsection{Mesoscopic simulation}

As an application a computer simulation of the observed evacuation was performed. Paths were obtained from the school evacuation plan. As regards the cost functions adopted, for fictitious links a constant speed function was considered; for corridors and descending flights relationships between speed and specific flow specified and calibrated in [36] has been considered.

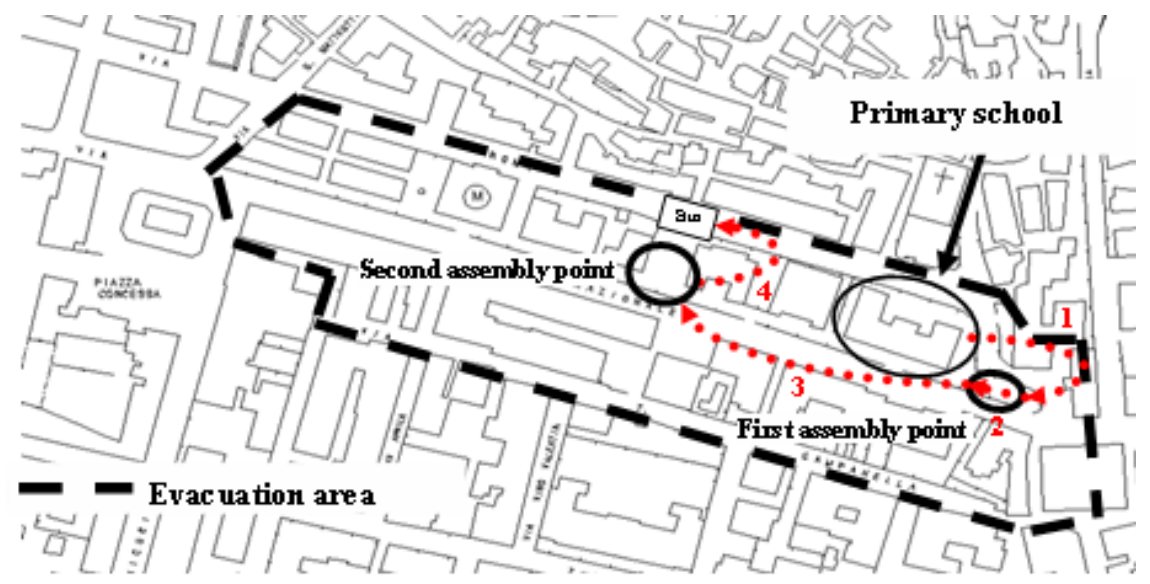

Figure 1: $\quad$ Phases of evacuation.

Demand values used in the simulation were obtained from school attendance on the experimentation day, and users were located in offices and classrooms following the real distribution. The demand value to be evacuated consists of about 150 users. Furthermore, in order to simulate evacuation more realistically, a path choice model was not implemented but adopted paths were obtained directly from the school evacuation plan.

The first three steps identified previously were simulated with a dynamic approach. The assignment model implemented within the DSS built for this research project allows pedestrian outflow to be simulated with two different hypotheses on distribution of departures:

- departures uniformly distributed in a defined interval;

- departures concentrated at the start of the first simulation interval.

The Dynamic Traffic Assignment (DTA) model considered here to simulate evacuation is mesoscopic and consists of an evolution of the dynamic approach 
developed for evacuation purposes applied in [34] for ship evacuation and in [35] as a support for the design of evacuation plans.

The approach used refers to discrete time intervals, supposed of constant length (without any loss in terms of generality). Let $\delta$ be the length of the generic interval $t$ and $\tau$ the current time within the interval, $\tau \in[0, \delta]$.

Outflow characteristics are calculated at the beginning of each interval (end of the previous one) and are assumed homogeneous along an arc. For sufficiently short lengths of the interval, they can be considered approximately constant for the entire duration of the interval, avoiding the need to allow for the inner fixed point problem that would arise. Once outflow characteristics on arcs for a generic interval are known, movement of users can be traced on the arc, depending on the definitions of the arc model and on the adopted movement rules described below.

\subsection{Macroscopic simulation}

A second application has been performed applying to the building an adaptation of the IMO guidelines [44] on evacuation analysis for passenger ships proposed in [45]. This application can be summarised in the following steps:

1. Schematization of escape routes as an hydraulic network where the pipes are the corridors and stairways, the valves are the doors and restriction in general and the tank are the public spaces.

2. Calculation of the density $\delta$ for all the escape routes.

3. Calculation of the initial specific flow $q_{s}{ }^{0}$, as a function of the densities.

4. Calculation of the flow $q$ for corridors and doors, in the direction of the assigned escape routes.

5. Calculation of the outlet calculated flows $q$ for each transition point.

6. Calculation, from the values of $M$ (number of persons entering a flight or a corridor) and of $q$, of the flow time $T_{F}$ for each stairway and corridor.

7. Calculation of travel time $T_{D}$ from the farthest point of escape route to the stairway.

8. Calculation, for each stair flight, of its travel time $T_{S}$. For each floor the total stair travel time is given by the sum of the travel times of all stairs flight connecting the floor with the assembly point.

9. Calculation of travel time from the end of the stairway to the assembly point.

10. Calculation of the overall time $T_{I}$ to travel along an escape route to the assembly point.

11. Once the calculation is performed for all the escape routes, the highest $T_{I}$ is selected for calculating the travel time as $T_{T}=\left(f_{1}+f_{2}\right) \cdot T_{I}$ where $f_{1}$ and $f_{2}$ are correction factors used to take into account of conditions of the simulated scenario and of counterflow. 


\subsection{Comparison of results}

Results obtained from the application of the above-described approaches have been expressed in terms of evacuation time. In Tab. 4 evacuation times for the considered phases related to experimentation and to simulations are reported.

Table 4: $\quad$ Comparison of evacuation time obtained from drill whit simulated ones.

\begin{tabular}{|c|c|c|c|}
\hline Phase & $\begin{array}{c}\text { Measured } \\
\text { time }\end{array}$ & $\begin{array}{c}\text { Meso } \\
\text { simulation }\end{array}$ & $\begin{array}{c}\text { Macro } \\
\text { simulation }\end{array}$ \\
\hline 1) evacuation of the building reaching first assembly point & $4 ' 14$, & $57^{\prime}$, & $43^{\prime}$, \\
\hline 2) roll-call of pupils at first assembly point & $3^{\prime} 05^{\prime}$ & $2 ’ 58^{\prime}$ & $3^{\prime} 00^{\prime \prime}$ \\
\hline 3) transfer to second assembly point & $2^{\prime} 00^{\prime \prime}$ & 1 '43', & 4’00", \\
\hline Total time & 9'19', & $10^{\prime} 28^{\prime \prime}$ & $11^{\prime} 23^{\prime \prime}$ \\
\hline
\end{tabular}

Some consideration can be made on the proposed approaches. For the first one (mesoscopic approach) the main advantage consists on the possibility to explicitly simulate queues and spill backs, whilst a drawback is given from the necessity to use a specific software. The second approach (macroscopic) gives an aggregate representation of flow conditions and does not allow a detailed analysis of them, on the other hand it can be easily implemented on a spreadsheet.

\section{Conclusions and perspectives}

The main result of this paper concerns both the application of a mesoscopic dynamic network assignment model in a multimodal context and the specification and calibration of some cost functions adopted in this model. A comparison between experimental data and simulation results shows how the usage of appropriate simulation models can realistically reproduce user behavior. It was shown that such models could be used as a support both to verify effectiveness of existing evacuation plans without resorting to expensive drills and to draw up evacuation plans. Implementation of appropriate cost functions can make the applied methodologies suitable for any building and/or area with homogeneous characteristics in terms of activities. Further investigations on travel time functions under different operative conditions are under development.

\section{References}

[1] Gwynne, S. Galea, E.R., Lawrence, P.J., Owen, M. \& Filippidis, L. A review of the Methodologies used in the Computer Simulation of Evacuation from the Built Environment. Building and Environment, 34, 741-749, 1999. 
[2] Fire Model Survey. International Survey of Computer Models for Fire and Smoke [on line] http://www.firemodelsurvey.com/EgressModels.html. Updated 2007

[3] Kuligowski, E.D. \& Peacock R.D. A Review of Building Evacuation Models. Technical note n. 1471. National Institute of Standards and Technology, Gaithesburgh, MD, 2005.

[4] Heskestad, A. W. \& Meland, O. J. Determination of Evacuation Times as a Function of Occupant and Building Characteristics and Performance of Evacuation Measures. In Human Behaviour in Fire -- Proceedings of the 1st International Symposium (pp. 673-680), 1998.

[5] ASERI (Advance Simulation of Evacuation of Real Individuals) A model to simulate evacuation and egress movement based on individual behavioural response, 2004. http://www.ist-net.de [On-line].

[6] Schneider, V. Application of the Individual-Based Evacuation Model ASERI in Designing Safety Concepts. In 2nd International Symposium on Human Behaviour in Fire (pp. 41-51). Boston, MA, 2001.

[7] Schneider, V. \& Konnecke, R. Simulating Evacuation Processes with ASERI. In Tagungsband International Conference on Pedestrian Evacuation Dynamics (PED) Duisburg, 2001.

[8] Gwynne, S., Galea, E. R., Lawrence, P., \& Filippidis, L. A Systematic Comparison of Model Predictions Produced by the buildingEXODUS Evacuation Model and the Tsukuba Pavilion Evacuation Data. Applied Fire Science, 7, 235-266, 1998.

[9] Gwynne, S., Galea, E. R., Owen, M., Lawrence, P., \& Filippidis, L. A Comparison of Predictions from the buildingEXODUS Evacuation Model with Experimental Data. In J. Shields (Ed.), (pp. 711-721). University of Ulster, 1998.

[10] Parke, J., Gwynne, S., Galea, E. R., \& Lawrence, P. Validating the buildingEXODUS Evacuation Model using Data from an Unannounced Trial Evacuation. In E.R. Galea, Editor, Proceedings of 2nd international pedestrian and evacuation dynamics conference, CMS Press, Greenwich, UK (2003) ISBN 1904521088, pp. 295-306

[11] Boyce, K., Fraser-Mitchell, J., \& Shields, J. Survey Analysis and Modelling of Office Evacuation Using the CRISP Model. In T. J. Shields (Ed.), Human Behaviour in Fire Proceedings of the 1st International Symposium (pp. 691-702), 1998.

[12] Fraser-Mitchell, J. Simulated Evacuations of an Airport Terminal Building, Using the CRISP Model. In 2nd International Symposium in Human Behaviour in Fire (pp. 89-100). Boston, MA, 2001.

[13] Kendik, E. Methods of Design for Means of Egress: Towards a Quantitative Comparison of National Code Requirements. In Fire Safety Science - Proceedings of the 1st International Symposium (pp. 497-511), 1995.

[14] Ketchell, N., Cole, S. S., \& Webber, D. M. The EGRESS Code for Human Movement and Behaviour in Emergency Evacuation. In R.A.Smith \& J. F. 
Dickie (Eds.), Engineering for Crowd Safety (pp. 361-370). London: Elsevier, 1994.

[15] Ketchell, N., Bamford, G. J., \& Kandola, B. Evacuation Modelling: A New Approach. In ASIAFLAM '95, Proceedings of the 1st International Conference on Fire Science and Engineering (pp. 499-505), 1995.

[16] AEA Technology. A Technical Summary of the AEA EGRESS Code Warrington, UK: AEA Technology, 2002.

[17] Francis, R. L. \& Saunders, P. B. EVACNET: Prototype Network Optimization Models for Building Evacuation (Rep. No. NBSIR 79-1593). Natl. Bur. Stand., (U.S.), 1979.

[18] Kisko, T. M., Francis, R. L., \& Nobel, C. R. EVACNET4 User's Guide, Version 10/29/98 University of Florida, 1998.

[19] Fahy, R. F. EXIT89 -- An Evacuation Model for High-rise Buildings Model Description and Example Applications. In Fire Safety Science -Proceedings of the 4th International Symposium (pp. 657-668), 1994.

[20] Fahy, R. F. EXIT89 -- High-rise Evacuation Model -- Recent Enhancements and Example Applications. In Interflam '96, International Interflam Conference -- $7^{\text {th }}$ Proceedings (pp. 1001-1005). Cambridge, England, 1996.

[21] Fahy, R. F. User's Manual, EXIT89 v 1.01, An Evacuation Model for HighRise Buildings Quincy, Ma: National Fire Protection Association, 1999.

[22] Levin, B. M. EXITT: A Simulation Model of Occupant Decisions and Actions in Residential Fires (Rep. No. NBSIR 88-3753). Natl. Inst. Stand. Technol., 1988.

[23] Levin, B. M. EXITT - A Simulation Model of Occupant Decisions and Actions in Residential Fires. In Fire Safety Science - Proceedings of the Second International Symposium (pp. 561-570), 1988.

[24] Deal, S. Technical Reference Guide for FPETool Version 3.2 (Rep. No. NISTIR 5486-1). Natl. Inst. Stand. Technol., 1995.

[25] Bensilum, M. \& Purser, D. A. Gridflow: an object-oriented building evacuation model combining pre-movement and movement behaviours for performance-based design. In 7th International Symposium on Fire Safety Science Worcester, MA: Worcester Polytechnic Institute, 2002.

[26] Kagarlis, M.A. Method of simulating movement of an autonomous entity through an environment. US Patent Application 20040059548. 2002.

[27] Berrou, J.L., Beecham, J., Quaglia, P., Kagarlis, M.A., Gerodimos, A. Calibration and validation of the Legion simulation model using empirical data. On line publication http://www.legion.com/about-us/Publications.php , 2005.

[28] Cappuccio, J. Pathfinder: A Computer-Based Timed Egress Simulation. Fire Protection Engineering, 8, 11-12, 2000.

[29] Klupfel, H. \& Meyer- König, T. Characteristics of the PedGo Software for Crowd Movement and Egress Simulation. . In E.R. Galea, Editor, Proceedings of 2 nd international pedestrian and evacuation dynamics conference, CMS Press, Greenwich, UK ISBN 1904521088 (pp. 331-340), 2003. 
[30] Meyer- König, T., Klupfel, H., \& Schreckenberg, M. A microscopic model for simulating mustering and evacuation process onboard passenger ships. In Proceedings of the International Emergency Management Society Conference. 2001.

[31] Buckmann, L. T. \& Leather, J. Modelling Station Congestion the PEDROUTE Way. Traffic Engineering and Control, 35, 373-377, 1994.

[32] Barton, J. and Leather, J. Paxport -- Passenger and Crowd Simulation. Passenger Terminal '95, 71-77, 1995.

[33] PAXPORT and PEDROUTE brochures (2004). http://www.halcrow.com [On-line].

[34] Di Gangi, M., Russo, F. \& Vitetta, A., A mesoscopic method for evacuation simulation on passenger ships: models and algorithms. In Pedestrian and Evacuation Dynamics 2003, pp. 197-208 CMS Press, London ISBN 1904521-08-8, 2003.

[35] Di Gangi, M., Approaching the analysis of transport networks in emergency conditions for the design of evacuation plans. In Risk Analysis $I V$, pp. 485-494, WIT Press. ISBN 1-85312-736-1, 2004.

[36] Di Gangi, M. \& Velonà, P., Safety of users in road evacuation: pedestrian outflow models in a building. In Urban Transport XIII, C. A. Brebbia (ed.), WIT Press, pp. 813-823, ISBN 978-184564-087-3, 2007.

[37] IES. Simulex User Manual; Evacuation Modeling Software. Integrated Environmental Solutions, Inc. Generic, 2001

[38] Thompson, P. A. Developing New Techniques for Modelling Crowd Movement. PhD Department of Building and Environmental Engineering, University of Edinburgh, Scotland, 1995.

[39] Thompson, P. A., Wu, J., \& Marchant, E. W. Modelling Evacuation in Multi-storey Buildings with Simulex. Fire Engineering, 56, 7-11, 1996.

[40] MacDonald, M. STEPS Simulation of Transient Evacuation and Pedestrian Movements User Manual. Unpublished Work, 2003.

[41] Hoffman, N. A. \& Henson, D. A. Simulating Transient Evacuation and Pedestrian Movement in Stations. In 3rd International Conference on Mass Transit Management Kuala Lumpur, Malaysia, 1997.

[42] Harrington, S. S. TIMTEX: A Hydraulic Flow Model for Emergency Egress. MSci Department of Fire Protection Engineering, University of Maryland, 1996.

[43] Shestopal, V. O. \& Grubits, S. J. Evacuation Model for Merging Traffic Flows in Multi-Room and Multi-Story Buildings. In Fire Safety Science -Proceedings of the 4th International Symposium (pp. 625-632), 1994.

[44] International Maritime Organization Guidelines for Evacuation Analysis for New and Existing Passenger Ships MSC.1/Circ.1238, 30 October 2007

[45] Di Gangi, M. \& Velonà, P. Deflusso pedonale negli edifici in condizioni di emergenza - modelli e metodi per la simulazione, applicazione ad un caso reale. Franco Angeli, Milano ISBN 978-884649-065-0, 2007. 